\title{
Towards Reading Acquisition: Bridging the Gap in Literacy Knowledge among At-Risk Arab Children
}

\author{
By Baha Makhoul ${ }^{*}$
}

\begin{abstract}
The study of Arabic language has mainly concentrated on the implications of its diglossic nature and orthographic features on reading acquisition while neglecting the conjoint effect of literacy related environmental factors. The current study attempts to investigate the remedial effects of early literacy promoting program among at-risk for reading difficulties Arab from kindergarten through 2 nd grade and asses its impact on reading acquisition in a diglossic context. 25 children from low socio-economic background have participated in this study and where compared to a group of 181 heterogenic students. The students were assessed for their discourse and listening comprehension skills, phonology, morphology, syntax and vocabulary in addition to their reading skills upon commencing 2nd grade. Despite the observed lag in literacy skills among the at-risk kindergarten children, the obtained results indicate that they were able to close the gaps in most of the literacy assessed domains but were significantly lower in reading achievements when compared to their peers.
\end{abstract}

\section{Introduction}

A comprehensive understanding of reading acquisition in Arabic requires insight on the various factors at interplay, including Arabic's diglossic nature, its orthographic features and early literacy environment. The aim of the present study was to shed a light on the role of early language skills development and socio-cultural factors in Arabic reading acquisition and the contribution of early screening and intervention.

Diglossia

The Diglossic nature of Arabic refers to the existing gap between its spoken and written form, resulting in two variations of the same language. Accordingly, spoken and literary Arabic differ in Vocabulary, grammar, syntax, linguistic and expression forms (Saeigh -Haddad, 2005; KhamisDakwar, 2007). In contrary to Spoken Arabic (SA), modern strand Arabic

${ }^{*}$ Lecturer, Researcher and Head of the Arabic Section at CET (Center for Educational Technology) Oranim Academic College, The Hebrew University, Israel. 
(MSA) is mainly acquired by formal teaching, following inadequate early exposure (Hudson, 2002).

The impact of such linguistic discrepancy on reading processes has drawn much interest along the past years, pointing to the immense challenge that it poses for Arab children upon commencing reading acquisition (Abu-Rabia, 2000; Saiegh-Haddad, 2003, 2004, 2005, 2007).

\section{Orthographical Features}

Arabic writing system includes 34 phonemes (28 consonants and 6 vowels). In addition, dialectical marks are added denoting short vowels that influence both phonological structure and meaning of the word (SaieghHaddad \& Henkin-Roitfarb, 2014; Mahfoudhi, Everatt \& Elbeheri, 2011). Thus, when vowelized, Arabic orthography is shallow and transparent but otherwise its considered deep orthography (Mahfoudhi et al., 2011).

The visual complexity of Arabic orthography is considered to be another impediment for reading acquisition (Abdelhadi, Ibrahim \& Eviatar, 2011; Ibrahim, Eviatar \& Aharon-Peretz, 2002). In Arabic, different letter shape's variations appear based on its position in the word (e.g. initial (ت), medial (ت) final $(ت)$ or separated $(ت)$ ) . In addition, the visual similarity of some of the letters constitutes another source of difficulty where letters are only distinguished by the number and position of dots appearing on or under it ( e.g. ث/ ت / ب).

\section{Literacy Acquisition in Arabic}

Emergent literacy skills are key factors for later reading acquisition. Accumulated scientific data has stressed the importance of establishing literacy rich environment for preschoolers ((Beals, DeTemple, \& Dickinson, 1994; Crain-Thoreson \& Dale, 1992; Rowe,1991; Snow et al., 1991; Bus, van IJzendoorn, \& Pellegrini, 1995).

Due to Arabic diglossic nature, the exposure to MSA during the early stages of language development is restricted where children are mainly exposed to SA. Such reality seems to affect the emergence of the required skills necessary for mastering reading and writing (Abu-Rabia, 2000; SaieghHaddad, 2003a, 2004, 2005, 2007a).

\section{Socio-economic Background and Literacy Acquisition}

The socio-economic background is thought to impact children's linguistic and cognitive development (Jednoróg K, Altarelli I, Monzalvo K, Fluss J, Dubois J, et al. (2012); Hackman, Farah, \& Meaney, 2010).It has been documented that already at early ages, children from low SES exhibit poor literacy skills including listening comprehension, discourse skills, phonology and vocabulary (Lundberg, Larsman, \& Strid, 2012; Fernald, Marchman, \& Weisleder, 2013; Hoff, 2006; Huttenlocher, Waterfall, Vasilyeva, Vevea \& Hedges, 2010). Accumulated scientific data indicates that emergent literacy skills are correlated with later reading achievements, especially phonological 
awareness (Muter, Hulme, Snowling, \& Stevenson, 2004; Roth, Speece, \& Cooper, 2002; Fletcher, Francis, Carlson, \& Foorman, 2004).

\section{The Current Study}

The aim of the current study is to investigate the conjoint effect of Arabic diglossic nature, its orthographic characteristics and SES on literacy skills and reading acquisition. Specifically, we assessed the effect of promoting literacy knowledge on later reading skills among low SES at risk children while following their progress from kindergarten throughout 2 nd grade.

The study questions:

- How will early literacy intervention reflect on technical reading skills?

- What is the effect of early promotion of literacy knowledge on reading comprehension?

\section{Method}

\section{Participants}

206 Arabic native $1^{\text {st }}$ graders, from five schools in northern Israel (one school was considered as low SES), were assigned to two groups. The control group included 108 students from high socio-academic background, 28 were incorporated in the low SES group. The social background of the students was determined by their school affiliation.

\section{Reading Literacy Program Procedure - "Arabic is our Language"}

Upon commencing $1^{\text {st }}$ grade, all the selected students participated in "Arabic is Our Language" reading program, which was founded on Adams interactive model (1991), taking into account the role of context, phonology, orthography and semantics and was adapted to the new curriculum of Arabic Language (the Israeli ministry of education, 2009). The program development was carried out by the Arabic language department team at the Center for Educational (CET).

The instructional format of the program included two stages, focusing on phonological awareness, orthographic knowledge, decoding skills, listening comprehension and discourse at the first stages while ultimately promoting reading fluency and reading comprehensions.

The program was carried by qualified teachers who underwent a comprehensive 30 hours training sessions, familiarizing them with the theoretical framework of the program as well as to its didactic instructional principles. In addition, they were supplied with a teacher's guide workbook, accompanying the contents appearing in the student books.

As part of the program, each student received two books divided into 5 and 7 units respectively, starting with alphabetical principles familiarization to 
advanced reading activities. Each unit included preparatory discourse activity, listening comprehension, writing and text reading activities in addition to review exercises and assessment tasks.

\section{Assessment Procedure}

At the end of preschool year, 45 minutes assessment test was administered individually to each student by qualified testers. The children were assessed for their literacy skills in several domains, including discourse, Listening comprehension, phonology, morphology, syntax and vocabulary. The same assessment procedure was conducted at the beginning of second grade.

Tools

To assess literacy competencies, a literacy assessment battery was used (Makhoul and Ibrahim, 2012) which included discourse Listening comprehension, Phonology and vocabulary measures. In addition, morphology task (Abu-Ahmed, 2008) and The Test of Receptive Oral grammar (Bishop, 1982) were included:

\section{Listening Comprehension}

Four measures were used to asses listening comprehension:

1) Story comprehension: a story recall tasks was followed after reading a story twice to the students. After the recall, they were asked to answer orally a series of comprehension question that addressed the various comprehension dimensions and were ultimately asked to recall the story after 20 min delay.

2) Instructions comprehension: 9 items were included in the test, requesting the students to follow the instructions of the tester. For example: "draw a kite above the longer pen.

3) Word-picture matching: the tester read a series of 5 sentences where the students were required to choose the sentence that best describes the presented picture.

4) Multi-dimensional listening comprehension test: the test is constituted of 3 parts. First, the students were asked to match a series of four sentences read by the tester to the corresponding pictures. At the second part, the students were presented with sentence completion task (i.e. a man is a king but a woman is ). Finally, the students heard three short passages, each followed by a question.

\section{Discourse}

Four subtests were included. In the first subtest, the students were asked to answer a series of question addressing their families, preferences and hobbies. In the $2^{\text {nd }}$ "picture description" subtest, the students were presented with picture and were asked to describe it. The $3^{\text {rd }}$ "story telling" subtest, the students were required tell a story following a presented picture. For the first two subsets, 
performance time was measured. The students' answers were evaluated with accordance to a performance indicator.

\section{Morphology}

Morphological awareness was assessed by Hanadi Abu-Ahmad task (2008) which was adapted to Arabic based on Shatil Test Battery (2002). The task consists of 20 items. It includes 2 items addressing the dual form, 4 items for grammatical gender forms, 8 items for possessive forms, 2 items for present tense verbs, 2 items for past tense verbs and 2 items for singular-plural forms. An answer was considered correct, only if the student was able to answer both the pseudo and real words pairs correctly.

\section{Syntax}

Test of Receptive Oral Grammar (Bishop, 1982) Arabic adaptation was used. The test was adapted by Hanadi Abu-ahmad (2008) to fit the syntactic and grammatical characteristics of Arabic .The students were presented with 4 pictures and were asked to select the picture corresponding to the heard word or sentence. The test was terminated following unsuccessful attempts in one or more of 5 successive items.

\section{Phonological Awareness}

Seven tasks were used at the first administration where another four task were added to the second assessment. All the used tasks were adapted to Arabic based on the Reading Readiness Screening Tool (RRST) developed by Learning Disabilities Association of Alberta (2009).

1) Auditory Word detection. Following two exemplary items, the students were presented with five sentences and were asked to count the number of the heard words following each sentence by using their fingers. The sentences were presented according to their difficulty level from easy to hard (i.e. number of words in a sentence). Each correct response was accredited 1 point while incorrect answer 0 points.

2) Syllable Detection. Following two exemplary items, the students were asked to map the number of syllable appearing in a heard word by clapping each syllable out. Each correct answer received 1 point.

3) Phoneme detection: the students were asked to sound the heard phonemes of the words. Due to the student's insufficient sensitivity to short vowels, when blended with consonant sounds. For example, the word "كََتَب" (/kataba/) consists of 3 consonants and 3 short vowels $(/ \mathrm{a} /)$ represented by the diacritical mark fatha (二) As a consequence, they were instructed to only sound consonant phonemes. In addition to two exemplary items, the task 
included 5 items which varied in their number of phonemes and word function. Each correct response received one point.

4) Rhyme generation. The task requires to generate a rhyming word with previously sounded target words or pseudo-words. 2 exemplary items and 6 additional items were included. Each correct response received one point.

5) Rhyme detection. A target picture was presented accompanied by 3 other pictures. The task assesses the students' ability to match the rhyming words by choosing the correct picture. To avoid alternate naming, the pictures were named by the tester. Two exemplary and ten additional items were presented. Each correct response received one point.

6) Initial sound isolation. The students were asked to isolate and sound the initial phoneme of each word they hear. Each correct response received one point.

7) Final sound isolation. The students were asked to listen to a word and isolate the last sound they hear. For example, "what is the last sound you hear in the word" (/qamar/)?. Following two exemplary items, 5 items were presented. Each correct response received one point.

8) Syllable blending. The students were asked blend the heard syllables (2-3 syllables) to form a word. Each correct response received one point. Two exemplary items were followed by five additional items. Each correct response received one point.

9) Phoneme blending. This task asses the students ability to blend the heard isolated phonemes (2-4 consonant sounds) into words. Each correct response received one point.

10) Syllable deletion. After hearing a word, the students were asked to sound the word after deleting a syllable. One exemplary and five other items were included. Each correct response received one point.

11) Phoneme isolation: The task requires recognizing the medial phoneme after hearing a word. Five items were presented in order of difficulty. Each correct response received one point.

\section{Vocabulary}

1) Expressive vocabulary. The students were tested on an Arabic adaptation of Learning disabilities association of Alberta expressive vocabulary Measure (2009). The test consists of two parts. The first part involves naming of 11 presented pictures, organized along three rows and five columns. In contrast, in the second part, the students are asked to point to the picture corresponding word they hear. For each part, both accuracy and time measure were considered for performance evaluation. For each correct response, 1 point was awarded. 
2) Generalization. The students were asked to draw a line between each pairs belonging to the same category. For example, socks and coat as winter clothing. Accuracy (overall correct responses) and time were measured.

3) Odd word out. Four pictures were presented and the students were instructed to draw a circle around the picture that doesn't belong and justify his answer.

4) Story sequencing. This task measures logical sequencing ability, vocabulary, language skills and etc. The students were presented with 4 pictures and were asked to sequence the pictures into correct order to create a story and tell it. For evaluation, morphological and syntactic agreement, sequencing (logical thinking), vocabulary, fluency and clarity of speech and narrative structure.

Reading and Reading Comprehension

The following tests were only administrated in the second assessment, after the students have acquired reading and writing skills. Both technical reading and reading comprehension were assessed:

1. Pseudo-word reading. Hanadi Abu-Ahmed (2008) pseudo reading measure was used to assess decoding skills. 6 items are introduced, including 1 exemplary item. Both accuracy and time were considered for evaluation. Each correct answer received one point .

2. Context-free Oral Word Naming. The students were asked to read five familiar words that they have previously been exposed to during the program. In addition, the students were presented with another five unfamiliar words (context free). Time and accuracy measures were used for performance evaluation.

3. Text reading and reading comprehension. The task incorporates 3 parts. First, the students were asked to read a short passage (11 words) and were assessed for their accuracy and reading fluency. Then, the students were asked to retell the story and were evaluated with accordance to story retelling performance index (see listening comprehension). Ultimately, the students answered a set of questions dealing with the read story. similarly, their level of performance was determined according to the story comprehension performance index (see listening comprehension).

$\begin{array}{cc}0 \text { points: } & \text { Task wasn't carried out } \\ 1 \text { point: } & \text { Poor performance } \\ 2 \text { points: } & \text { Intermediate } \\ 3 \text { points: } & \text { Advanced }\end{array}$




\section{Results}

To assess the progress in literacy performance among the comparison groups, an overall mean average score was calculated for each domain, both on the pretest and posttest. Within subject analysis was conducted to assess the students' progress across the program period.

\section{Listening Comprehension}

Prior to intervention (pre-test), significant difference in listening comprehension skills between the HG and LR group was obtained $(\mathrm{t}(204)=$ $2.69, \mathrm{p}<.01)$. In contrast, no significant effect was obtained in the post test (t $(40.4)=3.38, \mathrm{p}<.01)$.

A paired-sample t- test was conducted to assess the progress in each of the groups. Significant gain was obtained in listening comprehension skills for both LR and HG group ( $\mathrm{t}(24)=3.22, \mathrm{p}<.001),(\mathrm{t}(180)=5.04, \mathrm{p}<0.001)$, respectively.

\section{Discourse}

Before intervention, independent sample t-test was conduct to asses level of performance in discourse skills. No significant difference was obtained between LR $(M=49.68, S D=12.87)$ and HG group $(M=50.79, S D=11.5)$, as indicated by their overall mean scores and scores on the different discourse measures. In the post-test, the HG group showed a significantly higher level of performance when compared to the pre-test $(t(180)=6.29, p<.001)$. In contrast, no significant progress was noted in the LR group $(M=55.67, S D=9.86)$

\section{Phonology}

In the pretest, significant difference was encountered between the $\mathrm{HG}$ and LR group $(\mathrm{t}(204)=4.37, \mathrm{p}<0.0001)$. After the intervention, both HG and LR showed a significant progress in phonological skills $\mathrm{t}(205)=13.22, \mathrm{p}<.001)$; where no significant effect was obtained between $\mathrm{HG}((\mathrm{M}=70.82, \mathrm{SD}=12.46)$ and LR group $(\mathrm{M}=79.57, \mathrm{SD}=13.49)$.

\section{Syntax}

An initial significant difference was obtained between the HR and LR groups $(t(204)=2.51, p<.05)$. Significantly higher performance was obtained after the intervention $(\mathrm{t}(205)=9.18, \mathrm{p}<.001)$ where no significant difference was encountered between $\mathrm{LR}(\mathrm{M}=65.4, \mathrm{SD}=19.63)$ and $\mathrm{HG}$ group $(\mathrm{M}=68.43$, $\mathrm{SD}=16.69$ ).

\section{Morphology}

In the pretest, the HG group demonstrated significantly higher performance than the LR group $(\mathrm{t}(204)=2.84, \mathrm{p}<0.01)$. After intervention, a significant progress in performance was noted for both groups whereas no significant difference was obtained between the $\mathrm{HG}(\mathrm{M}=97.53, \mathrm{SD}=14.85)$ and LR group $(\mathrm{M}=74.8, \mathrm{SD}=16.96),(\mathrm{t}(205)=9.18, \mathrm{p}<.001$. 


\section{Vocabulary}

Between groups comparison showed no significant overall difference between the HG $(M=75.39, S D=10.4)$ and $L R$ group $(M=72.28, S D=10.48)$ in the pretest, although significantly higher performance was obtained among the HG group in the expressive vocabulary measure $(\mathrm{t}(204)=3.02, \mathrm{p}<.01)$.

The results indicate a significant overall progress in vocabulary after intervention among all students $(\mathrm{t}(205)=10.82, \mathrm{p}<.001)$. In the LR group, higher performance was obtained across all vocabulary measures when compared to their performance in the pretest. Similarly, higher performance in vocabulary measures was noted in the post- test in the HG group $(\mathrm{t}(180)=10.56, \mathrm{p}<.001)$ (see figure $1 \& 2)$.

Figure 1. Pre-test Differences in Groups Performance Scores (LR and HG)

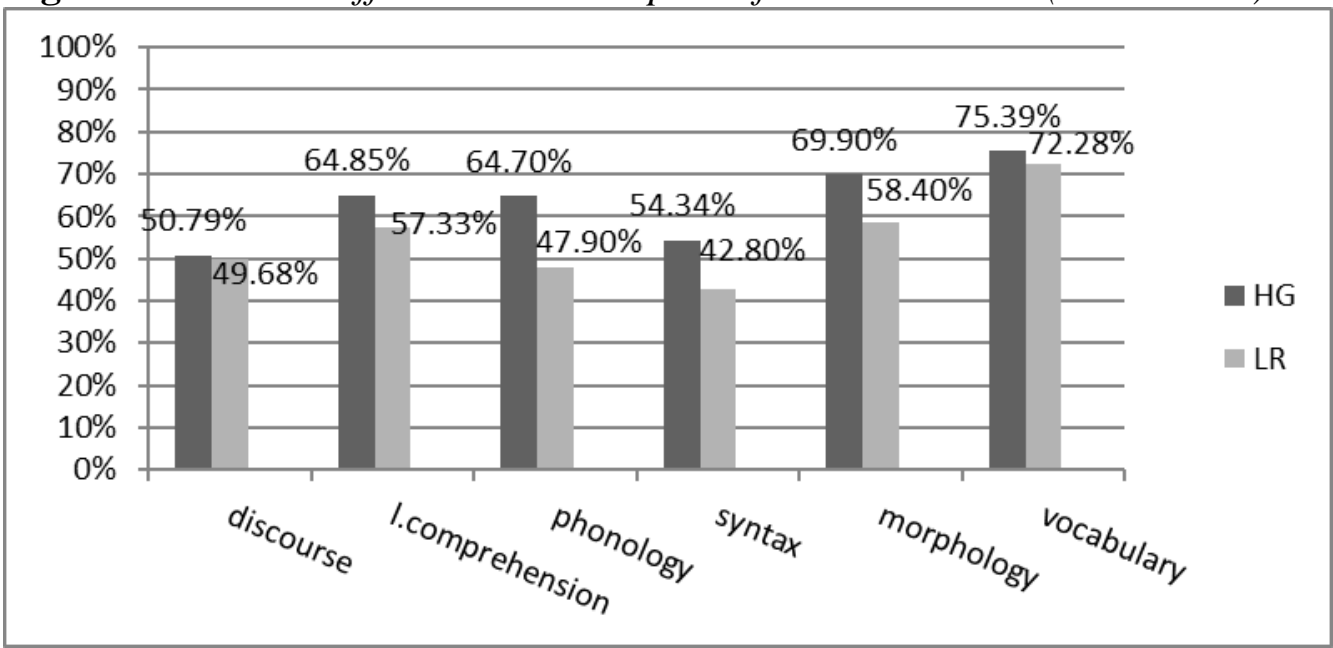

Figure 2. HG and LR Group's Achievement in Literacy Skills at the End of the Program

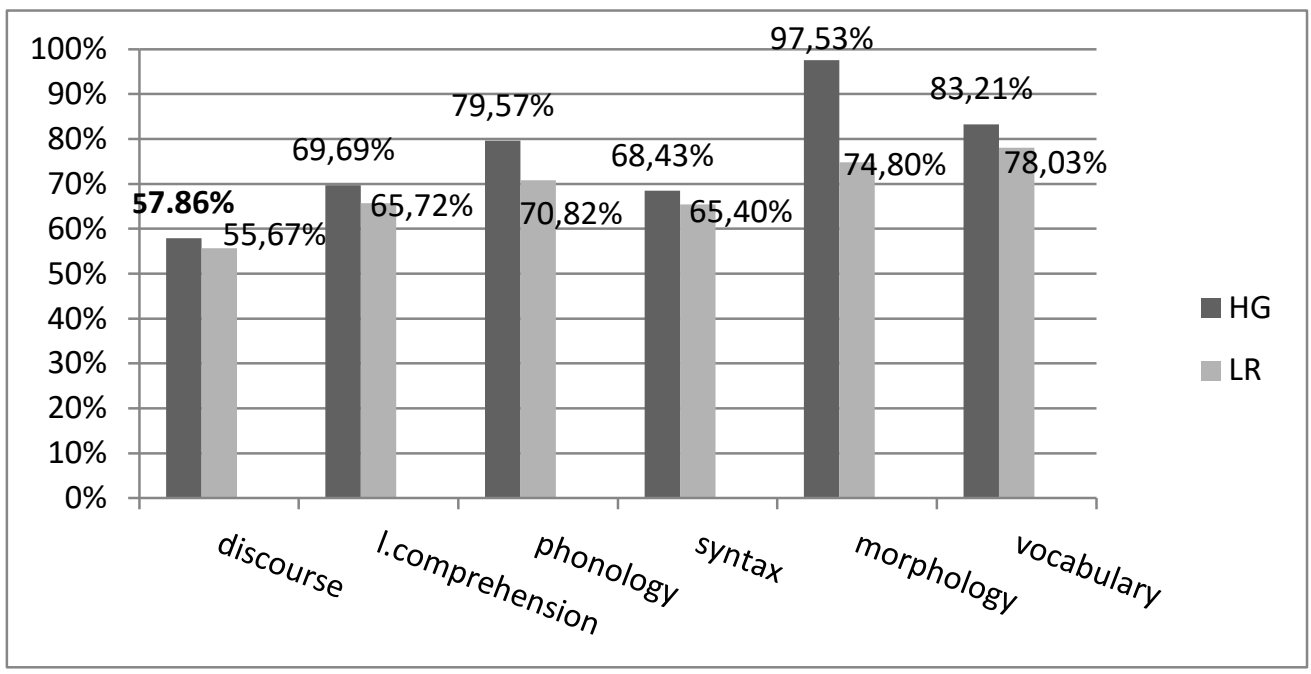




\section{Technical Reading and Reading Comprehension}

For technical reading ability an average mean score was calculated, composed of the mean scores in the pseudo-word, context-free and text reading measures. After the intervention, significantly higher technical reading performance was obtained in the HG group when compared to the LR group ( $\mathrm{t}(204)=5.61, \mathrm{p}<.001)$. LR showed significantly lower performance on all reading measure, including pseudo-word reading, context free word reading and text reading $(27.65)=3.09, \mathrm{p}<.01),(27.65)=4.53, \mathrm{p}<.001), \quad) \mathrm{t}(204)=5.57$, $\mathrm{p}<.001)$, respectively.

To evaluate the students reading comprehension skills, an average score was calculated based on their performance in the story recall and reading comprehension task. The obtained results points to a significant difference between the two groups in reading comprehension skills $(t(204)=4.88, p<.001)$ where higher performance was noted in the HG group $(M=66.32, S D=20.08)$ when compared to the LR group (see figure $3 \& 4$ ).

Figure 3. Technical Reading Attainments Difference between $H G$ and $L R$ Groups

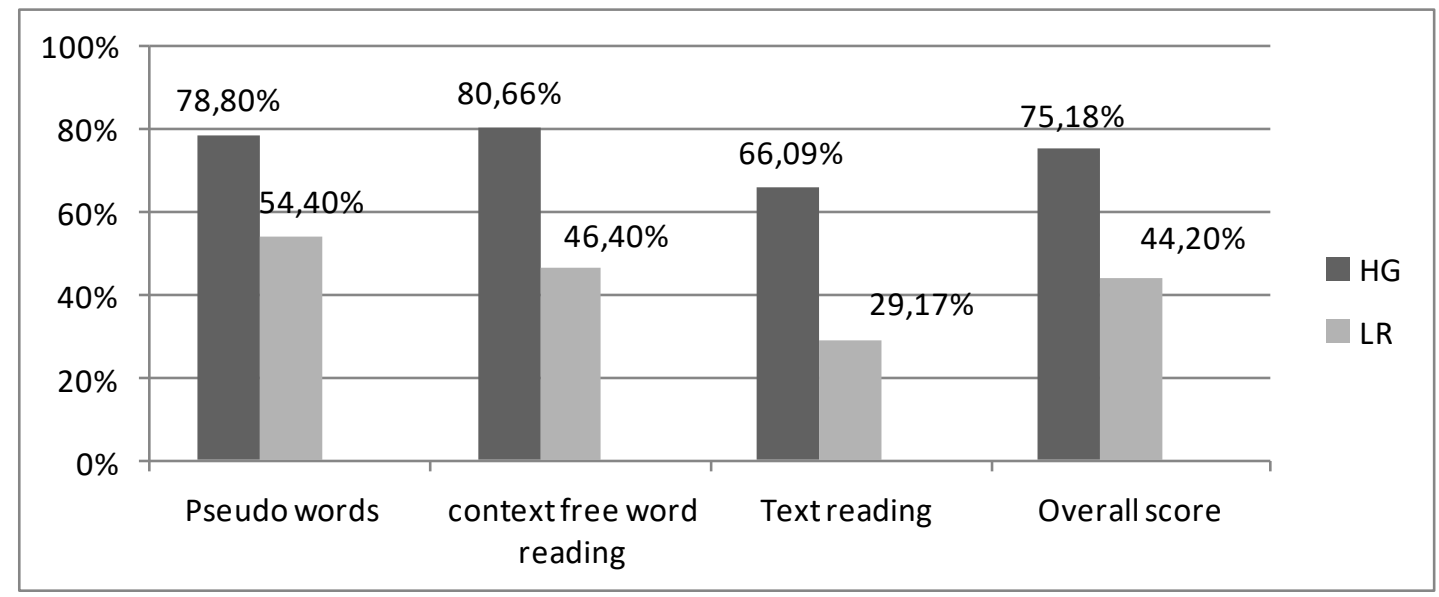

Figure 4. HG and LR Reading Comprehension Performance

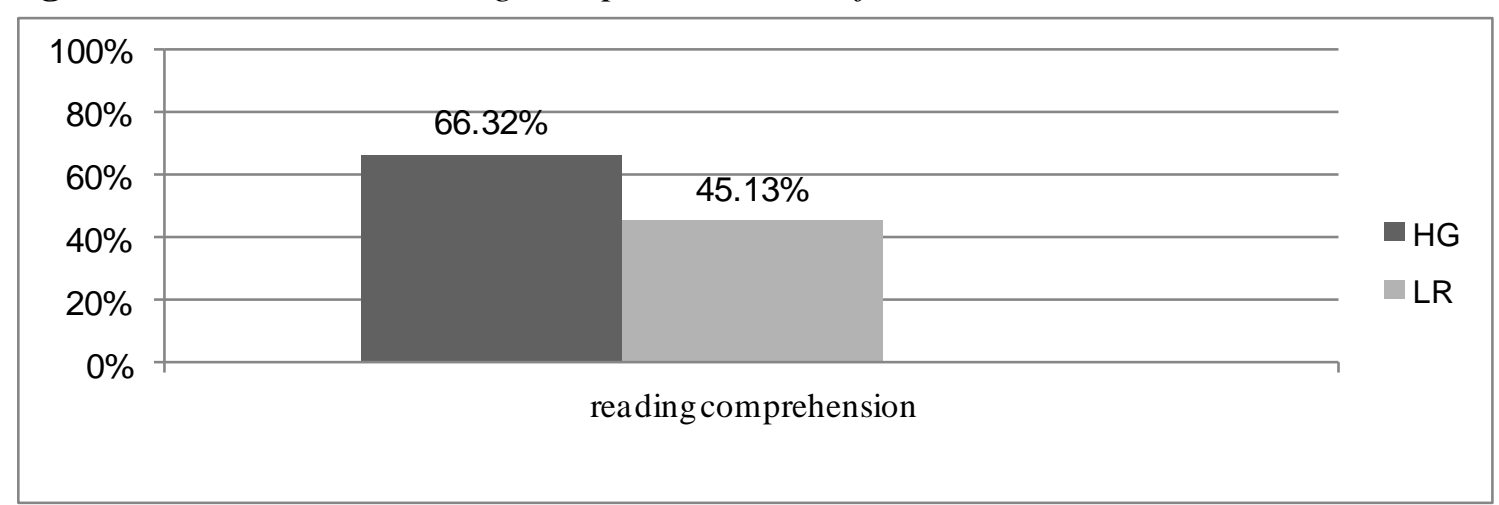




\section{Discussion}

The results of the current study affirm the necessity for comprehensive literacy promoting design, facilitating later reading acquisition, especially in light of the many complexities embodying Arabic language. Our results adds up to many scientific data stressing the vitality of adequate early literacy skills in establishing a solid ground for later literacy acquisition and academic success (Adams, 1990; Senechal, LeFevre, Smith-Chant \& Colton, 2001).

In this study, we addressed the effect of Low SES on the development of early literacy skills and reading acquisition, when combined with challenged imposed by Arabic diglossic nature and orthographic complexity. Accordingly, a multi-component literacy promoting program was devised and incorporated as part of Arabic's language curriculum in selected schools among $1^{\text {st }}$ grade Israeli Arabic native speakers who were selected upon finishing kindergarten. The program was carried for period of a year where the students were assessed on multiple literacy skills prior to program commencement and at its end, in addition to post-test reading skills assessment.

Preliminary literacy assessment emphasized the discrepancy in literacy skills between lower SES students (LR group) when compared to their counterparts from higher SES; where lower mastery of oral and listening comprehension skills, syntax and morphological awareness was noted. Such pattern of results coincide with other studies, pointing to the impact of socioeconomic context on array of emergent literacy capacities, where the former tend to depict lower phonological awareness, letter knowledge, vocabulary, grammar and oral skills, ultimately extending to reading and writing difficulties (Stipek \& ryan, 1997;Bowey, 1995; Kurdak \& Sinclair, 2001; Shatil, Share, \& Levin, 2000; Aram, Korat, Hassunah-Arafat, 2013). In the case of Arabic, the combined effect of SES and its socio-linguistic reality is thought to further obstruct normative development of literacy skills and reading acquisition (Aram et al., 2013; Saiegh-Haddad, 2003, 2004).

The current program has demonstrated its efficacy in bridging the gaps between low SES students and their peers from more advantageous socioeconomic background in different assessed literacy domains. Though, the achieved progress in discourse skills and in the expressive vocabulary wasn't significant where clear association between the measures is apparent. Recent approaches have stressed the necessity in attending oral language skills as a broader concept, including language processing abilities, grammar and vocabulary, which is affected by various language related experiences (e.g. home and school environment) thus requiring deep reflection on suitable and effective remedial methods, controlling for vast aria of intervening factors (Dickinson, McCabe, Anastasopoulos, PeisnerFeinberg, \& Poe, 2003; Hoff, 2003; Huttenlocher, Vasilyeva, Waterfall, Vevea, \& Hedges, 2007). In this respect, the results of the current study indicates to overall low discourse skills among both group regardless of SES status, emphasizing the effect of the 
linguistic discrepancy between Arabic spoken and written form (SaeighHaddad, 2005 ; Khamis-Dakwar, 2005).

With regard to reading and reading comprehension skills, the obtained results pointed to a significant difference in performance on the different reading measures between the LR group and HG group, where lower reading performance (accuracy and fluency) was observed among the former, despite the progress made in the different literacy measures. Additionally, the difficulties in technical reading skills were accompanied by lower performance in reading comprehension; for proficient reading is perquisite for deriving meaning, especially at early stages (e.g. Hoover Catts, Adlof, \& Weismer, 2006; Juel, Griffith, \& Gough, 1986). The current results further supports our assumptions and the relevancy of addressing the reciprocal nature of the different literacy skills, linguistic features of the language, environmental factors and reading processes in order to establish an effective longitudinal remedial programs that will meet the needs Arabic native speakers in their route to literacy and academic success.

\section{References}

Abdelhadi, S., Ibrahim, R., \& Eviatar, Z. (2011). Perceptual load in the reading of Arabic: Effects of orthographic visual complexity on detection. Writing Systems Research, 3(2), 117-127

Abu- Ahmed, H. (2008). Predictors of early reading ability in Arabic: a longitudinal study from kindergarten to grade 2. Unpublished M.A Dissertation University of Haifa, Faculty of Education, Department of Learning Disabilities.

Abu-Rabia, S. (2002). Reading in a root-based-morphology language: the case of Arabic. Journal of Research in Reading, 25(3), 299-309.

Adams, M. J. (1990).Beginning to read: Thinking and learning about print. Cambridge, MA: MIT Press.

Aram, D., Korat, O., \& Hassunah-Arafat, S. (2013). The contribution of early home literacy activities to first grade reading and writing achievements in Arabic. Reading and Writing, 26(9), 1517-1536.

Beals, D. E., De Temple, J. M., \& Dickinson, D. K. (1994). Talking and listening that support early literacy development of children from low-income families.

Bishop, D.(1982).TROG: Test of receptive grammar. Abingdon, Oxon: Thomas Leach (for Medical Research Council).

Bowey, J. A. (1995). Socioeconomic status differences in preschool phonological sensitivity and first-grade reading achievement. Journal of Educational Psychology, 87(3), 476.

Bus, A. G., Van Ijzendoorn, M. H., \& Pellegrini, A. D. (1995). Joint book reading makes for success in learning to read: A meta-analysis on intergenerational transmission of literacy. Review of educational research, 65(1), 1-21.

Catts HW, Adolf SM, Ellis Weismer S. Language deficits in poor comprehenders: A case for the simple view of reading. Journal of Speech, Language, and Hearing Research. 2006;49:278-293

Crain-Thoreson, C., \& Dale, P. S. (1992). Do early talkers become early readers? Linguistic precocity, preschool language, and emergent literacy. Developmental Psychology, 28(3), 421. 
Dickinson, D. K., McCabe, A., Anastasopoulos, L., Peisner-Feinberg, E. S., \& Poe, M. D. (2003). The comprehensive language approach to early literacy: The interrelationships among vocabulary, phonological sensitivity, and print knowledge among preschool-aged children. Journal of Educational Psychology, 95(3), 465.

Fernald, A., Marchman, V. A., \& Weisleder, A. (2013). SES differences in language processing skill and vocabulary are evident at 18 months. Developmental science, 16(2), 234-248.

Hackman, D. A., Farah, M. J., \& Meaney, M. J. (2010). Socioeconomic status and the brain: mechanistic insights from human and animal research. Nature Reviews Neuroscience, 11(9), 651-659.

Hoff, E. (2003). Causes and consequences of SES related differences in parent to child speech. InM. H. Bornstein \& R. H. Bradley (Eds), Socioeconomic status, parenting and child development(pp. 147-160). Mahwah, NJ: Erlbaum.

Hoff, E. (2006). How social contexts support and shape language development. Developmental Review, 26(1), 55-88.

HudsonA. 2002. Outline of a theory of diglossia. International Journal of the Sociology of Language, 157, 1- 48

Huttenlocher, J., Vasilyeva, M., Waterfall, H. R., Vevea, J. L., \& Hedges, L. V. (2007). The varieties of speech to young children. Developmental psychology, 43(5), 1062.

Huttenlocher J, Waterfall H, Vasilyeva M, Vevea J, Hedges LV. (2010) Sources of variability in children's language growth. Cognitive Psychology.61:343-365.

Ibrahim, R., Eviatar, Z., \& Aharon-Peretz, J. (2002). The characteristics of arabic orthography slow its processing. Neuropsychology, 16(3), 322.

Jednoróg, K., Altarelli, I., Monzalvo, K., Fluss, J., Dubois, J., Billard, C., ... \& Ramus, F. (2012). The influence of socioeconomic status on children's brain structure. PloS one, 7(8), e42486.

Juel, C., Griffith, P. L., \& Gough, P. B. (1986). Acquisition of literacy: A longitudinal study of children in first and second grade. Journal of educational psychology, $78(4), 243$.

Lundberg, I., Larsman, P., \& Strid, A. (2012). Development of phonological awareness during the preschool year: the influence of gender and socio-economic status. Reading and Writing, 25(2), 305-320.

Khamis-Dakwar, R. (2005). Children's attitudes towards the diglossic situation in Arabic and its impact on learning. Languages, Communities, and Education, 7586.

Khamis-Dakwar, R. (2007). The development of diglossic morphosyntax in Palestinian Arabic-speaking children. Columbia University.

Kurdak, L.A. \& Sinclair, R.J. (2001). Predicting reading and mathematics achievement in fourth-grade children from kindergarten readiness scores. Journal of Educational Psychology, 93 (3): 451-455

Mahfoudhi, A., Everatt, J., \& Elbeheri, G. (2011). Introduction to the special issue on literacy in Arabic. Reading and Writing, 24(9), 1011-1018

Makhoul, B., \& Ibrahim, R. (2012). Investigating Arabic reading acquisition in 1st grade following the interactive model. University of Haifa and Center for Educational Technology, Israel. (in Hebrew) 
Muter, V., Hulme, C., Snowling, M. J., \& Stevenson, J. (2004). Phonemes, rimes, vocabulary, and grammatical skills as foundations of early reading development: evidence from a longitudinal study. Developmental psychology, 40(5), 665.

Ministry of Education, (2009). Program of Teaching Arabic Language and Literature for the Arab Elementary Schools, Grades 1-6.Jerusalem: The Department of Learning programs.[In Arabic]

Roth, F. P., Speece, D. L., \& Cooper, D. H. (2002). A longitudinal analysis of the connection between oral language and early reading. The Journal of Educational Research, 95(5), 259-272.

Rowe, K. J. (1991). The influence of reading activities at home on students attitudes towards reading, classroom attentiveness and reading context: an application of structural equation modeling. British Journal of Educational Psychology, 61(1), 19-35.

Saiegh-Haddad, E. (2003a). Linguistic distance and initial reading acquisition: The case of Arabic diglossia. Applied Psycholinguistics, 24, 115-135

Saiegh-Haddad, E. (2004). The impact of phonemic and lexical distance on the phonological analysis of words and pseudowords in a diglossic context. Applied Psycholinguistics, 25, 495-512.

Saiegh-Haddad, E. (2005). Correlates of reading fluency in Arabic: Diglossic and orthographic factors. Reading and Writing, 18(6), 559-582.

Saiegh-Haddad, E. (2007). Linguistic constraints on children's ability to isolate phonemes in Arabic. Applied Psycholinguistics, 28(04), 607-625.

Saiegh-Haddad, E., \& Henkin-Roitfarb, R. The structure of Arabic language and orthography. Handbook of Arabic Literacy, 1.

Sénéchal, M., LeFevre, J. A., Smith-Chant, B. L., \& Colton, K. V. (2001). On refining theoretical models of emergent literacy the role of empirical evidence. Journal of School Psychology, 39(5), 439-460.

Shatil, E., Share, D. L., \& Levin, I. (2000). On the contribution of kindergarten writing to grade 1 literacy: A longitudinal study in Hebrew. Applied Psycholinguistics, 21(01), 1-21.

Snow, C. E., Barnes, W. S., Chandler, J., Goodman, I. F., \& Hemphill, L. (1991). Unfulfilled expectations: Home and school influences on literacy. Harvard University Press.

Schatschneider, C., Fletcher, J. M., Francis, D. J., Carlson, C. D., \& Foorman, B. R. (2004). Kindergarten prediction of reading skills: A longitudinal comparative analysis. Journal of Educational Psychology, 96(2), 265.

Stipek, D. J., \& Ryan, R. H. (1997). Economically disadvantaged preschoolers: ready to learn but further to go. Developmental psychology, 33(4), 711. 